\title{
Cera de Carnaúba
}

\author{
José Ademar M. Júnior ${ }^{1}$, Lana Grasiela Alves Marques ${ }^{2}$ \\ ${ }^{1}$ Universidade Federal do Piauí. Campus Ministro Petrônio Portella. CEP: 64049-550 Teresina-PI. \\ ${ }^{2}$ Núcleo de Inovação e Transferência de Tecnologia - NINTEC-UFPI Campus Ministro Petrônio Portella. \\ Centro de Convivência L09 e 10 CEP: 64049-550 Teresina-PI. (Igrasiela@hotmail.com)
}

\section{Objetivo}

A finalidade deste trabalho é mostrar o potencial tecnológico a partir da análise do número de patentes depositadas da carnaubeira que é uma palmeira nativa dos Estados do Piauí, Ceará e, em menor extensão, nos Estados do Rio Grande do Norte e do Maranhão.

\section{Aspectos tecnológicos}

A cera de Carnaúba é um produto natural obtido a partir da extração e processamento do pó cerífero das palhas da palmeira denominada Carnaubeira ou Carnaúba (Copernicia prunifera Mill.) $[1,2]$ planta típica do nordeste brasileiro. A obtenção da cera de carnaúba é basicamente artesanal com o corte de suas palhas e a consequente secagem, no qual é retirado o pó cerífero das folhas onde o mesmo está presente em película protetora existente em suas superfícies protegendo a planta da transpiração excessiva que ocorre em ambientes com longos períodos de estiagem e com baixa umidade relativa, uma característica predominante da região.

A cera possui na composição o triacontanol (TRIA) que na forma natural se encontra como um estér e a sua hidrólise o dispõem na forma de álcool. O TRIA é um álcool alifático de cadeia longa cuja fórmula química é $\mathrm{C}_{30} \mathrm{H}_{61} \mathrm{OH}$ [3]. De um modo geral, $85 \%$ da cera de carnaúba compõem de ésteres de ácidos graxos, além de pequenas porcentagens de ácidos graxos livres, de álcoois livres, além de pequena quantidade de resinas e hidrocarbonos. A cera apresenta alto ponto de fusão entre $83-85^{\circ} \mathrm{C}$.

Embora se saiba das inúmeras utilizações que se dão à cera de carnaúba, a indústria brasileira não possui o domínio sobre a tecnologia de transformação. A quase totalidade da cera produzida no país (estimase em mais de 95\%) é exportada na sua forma bruta. 0 domínio tecnológico brasileiro ocorre somente sobre produtos de limpeza e de polimento para assoalhos e automóveis, destinados ao mercado interno e, mais recentemente, sobre a emulsão para conservação de frutas [4], ainda em teste.

A cera de carnaúba é utilizada no mundo inteiro por diversos segmentos industriais como, por exemplo, na produção de ceras para polimento (pisos, sapatos e automóveis), na indústria de embalagens, na produção de tintas, de filmes contínuos, na indústria cosmética (batom, rímel e creme de barbear), produtos de tratamento de cabelo e pele, alimentícia e farmacêutica em revestimentos de cápsulas, cera dental, produtos de limpeza, filmes plásticos, adesivo e fotográficos. É usada na confecção de vernizes, esmaltes, lubrificantes, fósforo, isolantes, como também na composição de revestimentos, laqueadores e impermeabilizantes. $\mathrm{Na}$ papelaria, é componente para fabricação de papel-carbono, lápis de cera, cola e grafite [5]. As características físico-químicas da cera de carnaúba respondem pelo o seu largo emprego em eletrônica (chips e transistores) e no setor de informática, tanto na área de reprodução das informações como na produção de hardwares, tonners de impressoras e código de barra.

\section{Escopo}

A prospecção tecnológica para a cera de carnaúba foi realizada a partir do banco de dados do INPI (Instituto Nacional da Propriedade Industrial) utilizando como palavra-chave a expressão CERAAND CARNAÚBA* e no banco de patentes internacionais Espacenet (Escritório Europeu de Patentes) e USPTO (United States 
Patent and Trademark Office) como WAX AND CARNAUBA.

Os resultados foram direcionados a partir do banco de patentes espacenet, a escolha se dá por apresentar uma quantidade de informação mais completa sobre as patentes e permitindo também, o acesso às bases dos escritórios de propriedade industrial dos países membros, em comparação com os resultados do USPTO o qual apresentou um número elevado de patentes e ao INPI que apresentou uma patente.

Ao analisar as patentes encontradas no espacenet com o termo mais específico ( $w^{*}{ }^{*}$ and carnauba* and product* and cleaning*) obteve-se 12 registros.

Tabela de pesquisa por palavras-chave

\begin{tabular}{llll}
\hline Palavras-chave & INPI & EP & USPTO \\
\hline Cera de Carnaúba & 12 & 2128 & 10014 \\
Cera de Carnaúba Químico & 2 & 17 & 5394 \\
Cera de Carnaúba Cosmético & 0 & 26 & 2222 \\
Cera de Carnaúba Limpeza & 1 & 12 & 1590 \\
Cera de Carnaúba Revestimento & 1 & 80 & 4708 \\
Cera de Carnaúba Impermeabilizante & 2 & 33 & 0 \\
Cera de Carnaúba Lubrificante & 1 & 72 & 1861 \\
Cera de Carnaúba Verniz & 2 & 30 & 574 \\
Cera de Carnaúba Filmes Fotográficos & 0 & 3 & 491 \\
\hline
\end{tabular}

\section{Resultados e Discussão}

1. Evolução Anual de Depósitos de Patentes

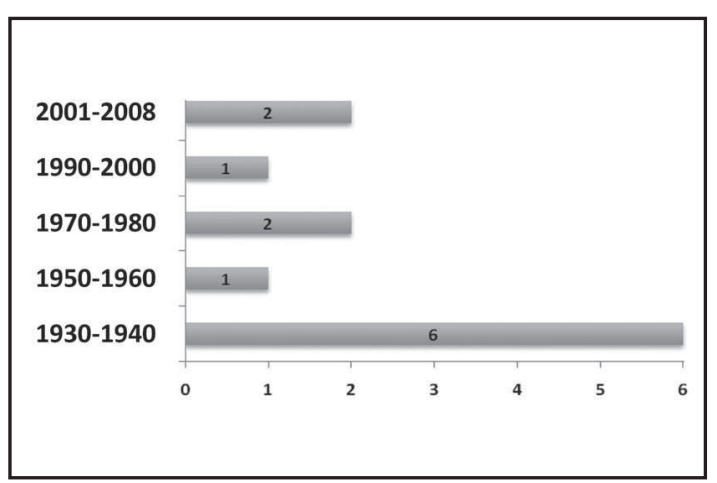

0 gráfico 1 mostra um elevando registro de patentes na década compreendida entre 1930 a 1940, justificado pelo aumento das exportações da cera de carnaúba, seguindo de uma queda na década de 90 onde as exportações baixaram consideravelmente.
2. Patentes Depositadas por País

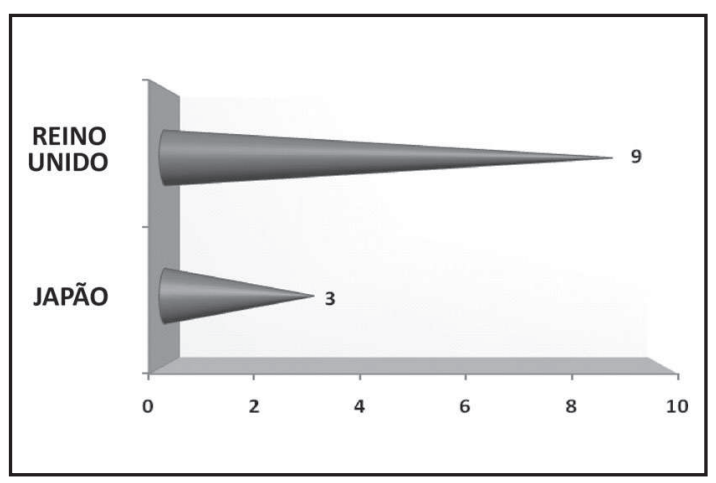

Os países do Reino Unido e Japão foram, entre as 12 patentes do EP, os únicos que depositaram patentes relacionadas com a cera de carnaúba em produtos de limpeza, sendo que os depósitos mais antigos são do Reino Unido. 
3. Patentes Depositadas por Seção de Classificação

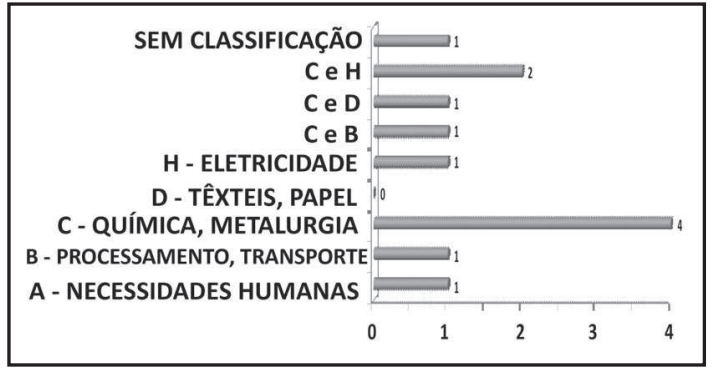

Observa-se um maior número de patentes classificadas na seção C, conforme classificação internacional, envolve química e metalurgia, pelo fato da cera de carnaúba ter muitas aplicações nessa área como na composição química dos produtos de limpeza.

4. Patentes relacionadas com alguns produtos de limpeza

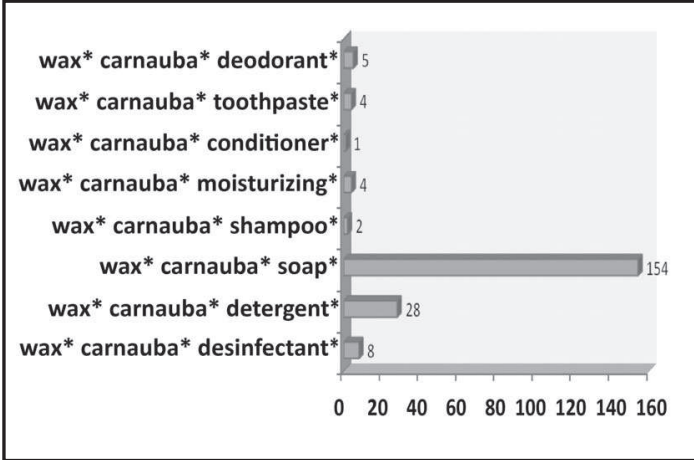

Quanto aos tipos de produtos de limpeza, observa-se um maior depósito de patentes relacionadas com sabonete (soap*) e com detergente (detergent*), sendo a cera de carnaúba aplicada na síntese destes produtos.

5. Relação entre número de patentes e depositantes

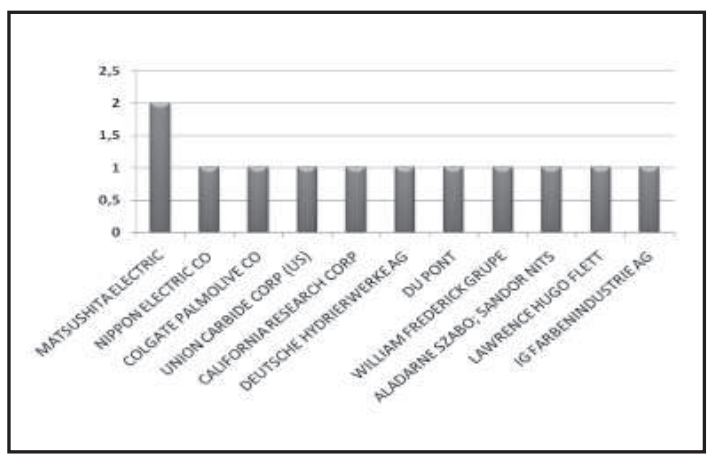

A maioria das patentes foram depositadas por empresas ou por um particular diferente. A empresa japonesa Matsushita Electric Works LTD é detentora de duas destas patentes.

\section{Conclusão}

A exportação da cera de carnaúba começou na década de 30 , onde os países exportadores começaram as pesquisas e patentear suas descobertas. O Reino Unido e o Japão foram os únicos que apresentaram patentes no EP, com cera de carnaúba e produto de limpeza.

A pesquisa apresentou um elevado número de patentes na área da química e metalurgia devido à cera de carnaúba ter uma vasta aplicabilidade principalmente nas indústrias químicas voltado na fabricação de sabonetes e detergentes.

Apesar de o Reino Unido ser o maior detentor das patentes analisadas, por outro lado, a empresa que mais depositou foi à japonesa Matsushita Electric Works LTD mostrando que o Japão destaca-se nesse tipo de produto.

De um modo geral, pode-se concluir que o baixo índice de patentes encontradas no banco de dados mostra que ainda falta uma exploração e desenvolvimento na utilização e aplicação do potencial tecnológico da cera de carnaúba a qual poderá contribuir para o progresso dos Estados do Piauí e Ceará.

\section{Referências}

1. Site: < http://www.seagri.ce.gov.br/ carnauba.htm>. Acessado em 26/06/08

3.<http://www.inova.unicamp.br/inventabrasil/ carnauc.htm> acesso em 28/06/2008.

3. Guerra, M.E.C.; Alves, A.F.; Oliveira, A.B.; Efeito da cera de carnaúba hidrolisada, na germinação e desenvolvimento de melão. UFC, Dept $^{\circ}$ de Fitotecnia.

4. Site: http://www.scielo.br/pdf/rbf/v25n3/ 18653.pdf> Acessado em 30/07/08

5. Site: <http://www.sfiec.org.br/artigos/ agroindustria/cera_carnauba_apresenta _multiaplicacoes.htm> Acessado em 26/06/08.

José Ademar M. Júnior é aluno de graduação em Química da UFPI. Este trabalho foi realizado no semestre de 2008.1 durante a disciplina optativa "Marcas, Patentes e Propriedade Industrial" ministrada pela

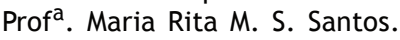

Lana Grasiela Alves Marques é bolsista do Núcleo de Inovação Tecnológica da UFPI. Participou anteriormente de cursos do INPI e de treinamentos da Rede NIT-NE. 